\title{
Do Cyclodextrins Encapsulate Volatiles in Deep
}

\section{Eutectic Systems?}

Maria Enrica Di Pietro** ${ }^{\dagger}$, Greta Colombo Dugoni ${ }^{\dagger}$, Monica Ferro ${ }^{\dagger}$, Alberto Mannu ${ }^{\dagger}$, Franca Castiglione $^{\dagger}$, Margarida Costa Gomes ${ }^{\ddagger}$, Sophie Fourmentin ${ }^{\square}$, and Andrea Mele ${ }^{\dagger}$.

${ }^{\dagger}$ Department of Chemistry, Materials and Chemical Engineering “Giulio Natta”, Politecnico di Milano, Piazza Leonardo da Vinci 32, 20133 Milan, Italy.

${ }^{\ddagger}$ Laboratoire de Chimie, Ecole Normale Supérieure de Lyon \& CNRS, 46 Allée Italie, 69364 Lyon Cedex 07, France.

${ }^{\square}$ Unité de Chimie Environnementale et Interactions sur le Vivant (UCEIV) EA 4492, SFR Condorcet FR CNRS 3417, Université du Littoral Cote d’Opale (ULCO), 145 Av. M. Schumann, 59140 Dunkerque, France.

* mariaenrica.dipietro@polimi.it; andrea.mele@polimi.it

\section{KEYWORDS}

NADES - Volatile Organic Compounds - Host-guest complex - NMR spectroscopy Association constant - Dynamics. 


\section{ABSTRACT}

Efficient renewable and non-toxic absorbents can now be designed to eliminate air pollutants such as volatile organic compounds (VOCs) from confined atmospheres. New hybrid materials result from the combination of Deep Eutectic Systems (DES) with well-known VOCs capture agents like $\beta$-cyclodextrin $(\beta C D)$. Yet, a question arises: does $\beta C D$ retain its encapsulation ability in DES? Multiple NMR techniques are used here to demonstrate the formation of inclusion complexes of $\beta C D$ with two VOCs, aniline and toluene, in the pure DES reline and in reline/water mixtures. Complexation-induced chemical shift changes and intermolecular hostguest NOEs in the rotating frame give evidence of a genuine encapsulation in the $\beta C D$ cavity, and complementary information on the dynamics of the VOC is gathered via relaxation and diffusion experiments. This work shows how different NMR techniques can contribute to the design of task-specific sustainable materials for absorption/extraction processes.

\section{INTRODUCTION}

Volatile Organic Compounds (VOCs) are among the most common air pollutants emitted from chemical and petrochemical industries, transportation vehicles and commercial products such as

solvents, paints, cleaners, and lubricants. ${ }^{1-3}$ It is today compulsory in many countries to limit and control VOCs emissions both in terms of environment, since they affect the climate change and the growth and decay of plants, and in terms of human and animal health, since VOC exposure causes respiratory distress, eye and throat irritation, neurological toxicity, and cancer, among other effects. $^{1-3}$ In the presence of sunlight, VOCs may react with nitrogen oxides and other 
airborne chemicals to form ozone, leading to various environmental hazards. ${ }^{4}$ VOCs removal is hence a major concern of the society's commitment towards the ecosystem. ${ }^{1}$

Among the materials used as VOC capture agents, $\beta$-cyclodextrin $(\beta C D)$ is one of the most attractive. ${ }^{2,5-8} \beta \mathrm{CD}$ is a torus-shaped cyclic oligosaccharide made up of seven $\alpha-1,4$-linked Dglucopyranose units. It can form inclusion complexes by entrapping small hydrophobic molecules (guests) in the hydrophobic cavity of the macrocyclic sugar (host) through noncovalent host-guest interactions. This is especially true if the target molecules contain hydrophobic groups, such as phenyl groups that are present in many VOCs. ${ }^{9} \beta C D-b a s e d$ materials have been reported to be efficient in inclusion complex formation towards several organic pollutants. ${ }^{2,3,5,6,10-14}$

Deep Eutectic Systems (DES) have been recently suggested as innovative materials with potential in gas absorption. ${ }^{15-18}$ Practically speaking, a DES is the result of the combination in the proper ratio of an opportune hydrogen-bond donor (HBD) and a hydrogen-bond acceptor (HBA). ${ }^{19-21}$ Self-association of the HBD and HBA lowers the entropic difference of the phase transition, so that basically a eutectic is formed with a depressed freezing point that lies well below that of the individual components. DES show many beneficial characteristics: among other, they can be prepared from cheap, readily available, and toxicologically well characterized starting materials, which also implies low cost. A large number of different combinations of HBA and HBD has been reported and their use proposed in many fields of application. ${ }^{22-25}$ Interestingly, studies using static headspace gas chromatography (SH-GC) on choline chlorideor tetrabutylphosphonium bromide-based DES showed they can be good candidates for VOC absorption processes. ${ }^{15}$ 
In this context, $\mathrm{DES} / \beta \mathrm{CD}$ mixtures are likewise of interest as new hybrid materials, since in principle their individual absorbing/sequestrating properties may be mutually reinforced. Indeed, the complexation ability of several native and substituted cyclodextrins in the DES reline (choline chloride:urea at 1:2 molar ratio, ChU) towards four VOCs (dichloromethane, toluene, tert-butylcyclohexane and limonene) has been recently investigated via SH-GC. ${ }^{26}$ The authors showed a decrease of the chromatographic peak area, which indicates a higher solubilization of the VOC in the mixture. No further information on the retention mechanism - whether genuine inclusion or aggregation or other - is unfortunately accessible by means of SH-GC. Yet, to concretely exploit reline/ $\beta C D$ mixtures for capturing toxic contaminants, a better characterization of the guest-host inclusion complex at the molecular level is crucial.When searching for an alternative and/or complementary technique to study interactions of small molecules with supramolecular hosts and in particular for investigating the formation of inclusion complexes, Nuclear Magnetic Resonance (NMR) spectroscopy is probably the best option. It is not only possible to directly probe the genuine inclusion of the guest in the CD cavity, but the large number of spectral parameters that can be measured and analysed give also access to unique qualitative and quantitative information., ${ }^{7,9,27-30}$ In the present work, we demonstrate that the measurement of different NMR parameters is extremely beneficial to investigate the sorption behaviour of $\beta C D$ towards selected VOC in the DES reline (see Fig. 1 for structures). First, complexation-induced chemical shift changes and intermolecular host-guest NOEs in the rotating frame allow us to assess whether or not a genuine encapsulation occurs in $\mathrm{ChU} / \beta \mathrm{CD}$ mixtures. Moreover, Diffusion Ordered SpectroscopY (DOSY) experiments and measurements of non-selective and selective spin-lattice relaxation times $\left(\mathrm{T}_{1}^{\mathrm{NS}}\right.$ and $\mathrm{T}_{1}^{\mathrm{SE}}$ ) are applied to glean additional insights into the dynamics of the guest molecule. 
A practical limitation in $\mathrm{ChU} / \beta \mathrm{CD}$ systems is the relatively high density and viscosity of the mixtures, which strongly reduces the resolution in NMR spectra. Luckily, DES readily lend themselves to be added with a considerable amount of water without losing their unique properties. The effect of water on the hydrogen-bonding network of a DES is still debated and it is generally accepted that reline keeps its nanostructure up to water concentrations of about 35 wt\% and a transition from a "water-in-DES" to a "DES-in-water" regime only occurs at ca. 50 wt $\% .^{31,32}$ The possibility to reduce DES viscosity while preserving its molecular interactions and structure is an extremely advantageous feature, if one considers that DESs are highly hygroscopic and latent absorbed water is unavoidable, especially in the context of industrial applications. This holds true also in the presence of $\beta C D$. Indeed, some of us have recently demonstrated that in reline $/ \beta C D / \mathrm{H}_{2} \mathrm{O}$ systems, $\beta$-cyclodextrin interacts primarily with the added water, while reline preserves a residual molecular network. ${ }^{33}$ In this mixture, $\beta C D$ benefits of enough mobility to retain its encapsulation properties, as proved by selective variation of the chemical shifts and ROESY host-guest intermolecular correlations in the case of a model drug, namely the anti-inflammatory drug piroxicam.

Here we intend to apply multiple NMR experiments to investigate more deeply the potential of reline/ $\beta \mathrm{CD}$ mixtures for $\mathrm{VOC}$ absorption in the absence and presence of water. As model compounds, we selected two major volatile organic compounds in the environment, aniline and toluene (Figure 1), which are listed as hazardous air pollutants in the Clean Air Act by the US Environmental Protection Agency (https://www3.epa.gov/ttn/atw/orig189.html). The formation of genuine inclusion complexes is evaluated and the dynamic properties of the guest molecules investigated. 


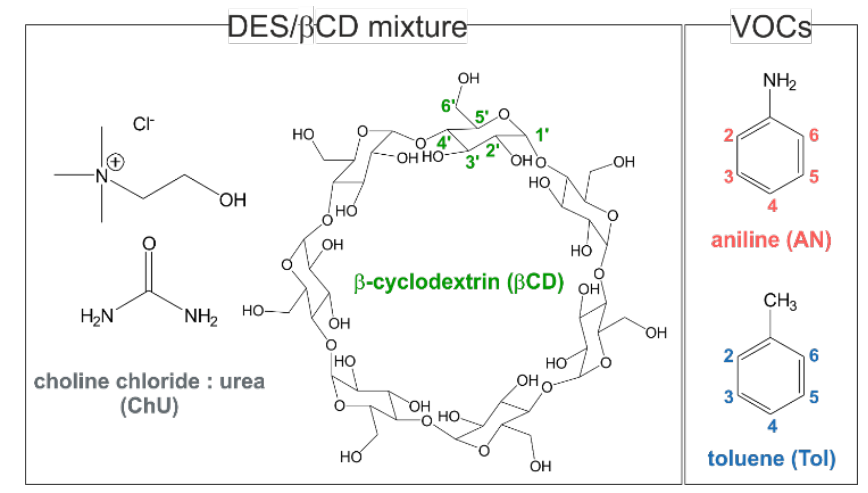

Figure 1. Structure and numbering of compounds used in this work.

\section{EXPERIMENTAL SECTION}

A summary of all samples used is reported in Table 1. The deep eutectic solvent reline (ChU) was prepared by the heating method, which consists in mixing the two components [Ch]Cl and $\mathrm{U}$ at molar ratio $1: 2$ and then heating at $80{ }^{\circ} \mathrm{C}$ under constant stirring until a homogeneous liquid is formed. In all samples containing $\beta$-cyclodextrin, $10 \%$ in weight of $\beta \mathrm{CD}$ was added to the reline under stirring at room temperature, until the formation of a homogenous liquid. In all hydrated samples, 210 equivalents of water with respect to $\beta C D$ were added under stirring. As there are 3 hydroxyl groups for each of the 7 glucose units in a single $\beta C D$ molecule, this corresponds to a mole ratio $\beta C D$ :added $\mathrm{H}_{2} \mathrm{O}$ equal to $1: 10$. As reline was not dried prior to utilization, also not hydrated samples contain traces of water due to DES's hygroscopic nature. The water content of the freshly prepared solutions was determined using a KF coulometric titrator from Mettler Toledo and was found equal to $2.1 \%$ for $\mathrm{ChU} / \beta \mathrm{CD}$ and $0.5 \%$ for $\mathrm{ChU}$. Overall this translates into a total water content in hydrated samples between 25 and $27 \mathrm{wt} \%$, which is below the expected transition to an aqueous solution. Samples 1 to $\mathbf{4}$ were prepared by adding either aniline or toluene to the $\mathrm{ChU} / \beta \mathrm{CD}$ and $\mathrm{ChU}$ solvents. Samples 5 to $\mathbf{8}$ were prepared by adding the same 
VOCs to the corresponding hydrated systems, $\mathrm{ChU} / \beta \mathrm{CD} / \mathrm{H}_{2} \mathrm{O}$ and $\mathrm{ChU} / \mathrm{H}_{2} \mathrm{O}$. All samples containing $\beta C D(\mathbf{1}, \mathbf{3}, \mathbf{5}$ and $\mathbf{7})$ were prepared to have a final host/guest molar ratio of 1:1 and the same weight percentage of VOC was also used in samples without $\beta C D(2,4,6$ and 8$)$. Samples $\mathbf{9}$ and $\mathbf{1 0}$ without VOCs were used as references. The samples for NMR analysis were placed in standard $5 \mathrm{~mm}$ tubes and multiple NMR experiments were performed (details are given in the SI).

Table 1. Composition of samples used in this work.

\begin{tabular}{|l|l|l|l|l|l|}
\hline Sample & Short name & DES & $\boldsymbol{\beta C D}$ & Added $\mathbf{H}_{2} \mathbf{O}$ & Guest molecule \\
\hline $\mathbf{1}$ & $\mathrm{ChU} / \beta \mathrm{CD} / \mathrm{AN}$ & $\mathrm{ChU}$ & $10 \%$ & - & AN (1 eq.) \\
\hline $\mathbf{2}$ & $\mathrm{ChU} / \mathrm{AN}$ & $\mathrm{ChU}$ & - & - & AN $(1$ eq. $)$ \\
\hline $\mathbf{3}$ & $\mathrm{ChU} / \beta \mathrm{CD} / \mathrm{Tol}$ & $\mathrm{ChU}$ & $10 \%$ & - & Tol (1 eq.) \\
\hline $\mathbf{4}$ & $\mathrm{ChU} / \mathrm{Tol}$ & $\mathrm{ChU}$ & - & - & Tol $(1$ eq. $)$ \\
\hline $\mathbf{5}$ & $\mathrm{ChU} / \beta \mathrm{CD} / \mathrm{H}_{2} \mathrm{O} / \mathrm{AN}$ & $\mathrm{ChU}$ & $10 \%$ & 210 eq. & AN $(1$ eq. $)$ \\
\hline $\mathbf{6}$ & $\mathrm{ChU} / \mathrm{H}_{2} \mathrm{O} / \mathrm{AN}$ & $\mathrm{ChU}$ & - & 210 eq. & AN $(1$ eq. $)$ \\
\hline $\mathbf{7}$ & $\mathrm{ChU} / \beta \mathrm{CD} / \mathrm{H}_{2} \mathrm{O} / \mathrm{Tol}$ & $\mathrm{ChU}$ & $10 \%$ & 210 eq. & Tol $(1$ eq. $)$ \\
\hline $\mathbf{8}$ & $\mathrm{ChU} / \mathrm{H}_{2} \mathrm{O} / \mathrm{Tol}$ & $\mathrm{ChU}$ & - & 210 eq. & Tol (1 eq.) \\
\hline $\mathbf{9}$ & $\mathrm{ChU} / \beta \mathrm{CD}$ & $\mathrm{ChU}$ & $10 \%$ & - & - \\
\hline $\mathbf{1 0}$ & $\mathrm{ChU} / \beta \mathrm{CD} / \mathrm{H}_{2} \mathrm{O}$ & $\mathrm{ChU}$ & $10 \%$ & 210 eq. & - \\
\hline
\end{tabular}

\section{RESULTS AND DISCUSSION}

Does $\beta$-cyclodextrin form inclusion complexes with VOCs in pure (non-hydrated) reline? 
It is well known that NMR chemical shift is sensitive to changes in electronic environment. Hence, comparing the observed chemical shifts of guest protons as well as of protons located in the CD cavity $\left(\mathrm{H}_{3}\right.$, and $\mathrm{H}_{5}$ ') in the ${ }^{1} \mathrm{H}$ 1D spectra of their mixture compared to pure components give a first clue on the formation of an inclusion complex. Figure 2 shows selected regions of ${ }^{1} \mathrm{H}$ spectra corresponding to VOC's signals for the case of aniline (AN) and toluene (Tol) in reline, with or without $\beta C D$. In the presence of $\beta C D$, it is observed the expected downfield shift of the peaks of the guest molecule, which suggests the formation of $\beta \mathrm{CD} / \mathrm{VOC}$ inclusion complexes (see Table S1 for complexation-induced chemical shifts). ${ }^{30}$ Moreover, a considerable line broadening of the aromatic peaks is observed after the addition of $\beta C D$, which might indicate an exchange regime between free and encapsulated species. Overall, the variation of the chemical shifts as well as the line broadening are more prominent in the case of toluene than aniline, which might point towards a stronger interaction of the former with $\beta C D$. Unfortunately, nonhydrated reline mixtures are highly viscous, which causes short relaxation times, broad lines and overall poorly resolved spectra. The effect is even more relevant of $\beta C D$ 's signals, which also suffer from severe overlap with peaks of choline (see Figs. S1-S2). Therefore, any further analysis of ${ }^{1} \mathrm{H}$-NMR spectra is not possible. Aiming at confirming the formation of $\beta \mathrm{CD} / \mathrm{VOC}$ inclusion complexes, we performed rotating-frame Overhauser (ROESY) experiments (Fig. S3). Again, the signal loss due to the short relaxation time in the highly viscous DES solutions made it impossible to distinguish any intermolecular host-guest cross peaks. 


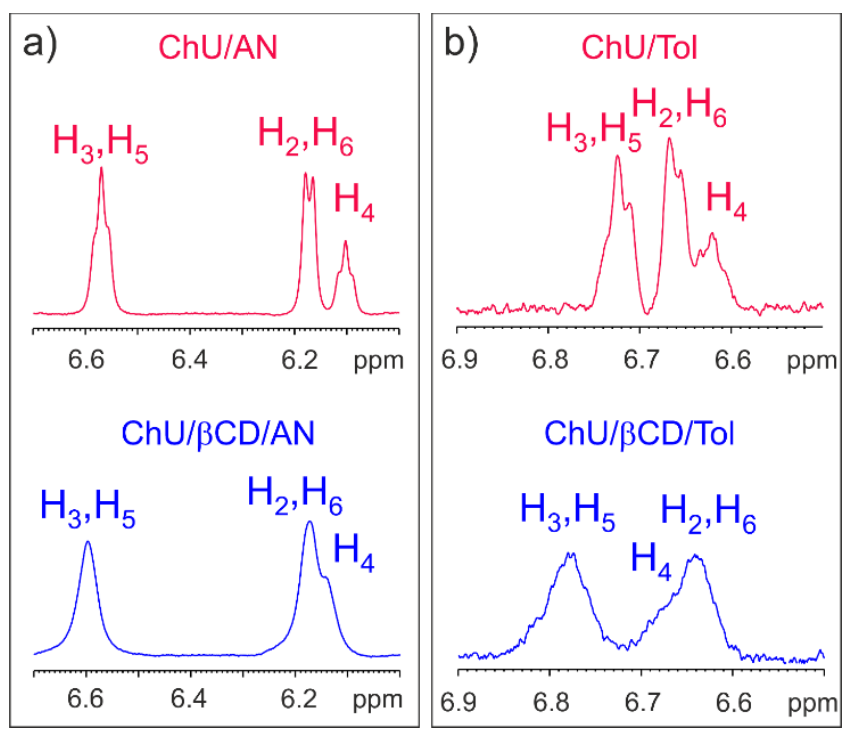

Figure 2. Selected regions of ${ }^{1} \mathrm{H}$ NMR spectra corresponding to aromatic protons of (a) AN samples $\mathrm{ChU} / \mathrm{\beta CD} / \mathrm{AN}$ (bottom, in blue) and ChU/AN (top, in red) and (b) Tol in samples $\mathrm{ChU} / \beta \mathrm{CD} / \mathrm{Tol}$ (bottom, in blue) and ChU/Tol (top, in red).

Given the poor quality of $\beta C D$ signals, we focused on aromatic peaks of VOCs, which are relatively far from DES’s signals and give detectable signals. Well-established NMR methods to study inclusion complexes from the guest's viewpoint are relaxation and diffusion experiments. The use of relaxation NMR spectroscopy to study aggregation and/or complexation is well known and relies mostly on the use of inversion recovery experiments for the measurement of proton non-selective and selective spin-lattice relaxation rates, $\mathrm{R}_{1}^{\mathrm{NS}}$ and $\mathrm{R}_{1}^{\mathrm{SE}} \cdot{ }^{27,29,34}$ Indeed, assuming that the bound and free states interconvert quickly with respect to both chemical shift difference and proton relaxation rate, the formation of inclusion complexes affects $\mathrm{R}_{1}^{\mathrm{NS}}$ and $\mathrm{R}_{1}^{\mathrm{SE}}$ at different extents. In particular, it has been shown that $\mathrm{R}_{1}^{\mathrm{SE}}$ is more sensitive to the slower rotational tumbling of the complex than $\mathrm{R}_{1}^{\mathrm{NS}} \cdot{ }^{28,35-39}$ Therefore, the combination of non-selective and selective inversion recovery measurements is a rich source of information in dynamic 
studies. It has been used extensively to measure chemical exchange rate constants separated from the spin-lattice relaxation rates in slow exchanging systems, ${ }^{40}$ to describe molecular conformational motion in solution, ${ }^{41,42}$ as well as to study interactions between small molecules with macromolecules, ${ }^{28,29,37,38}$ and estimating the binding affinities of ligands with protein. ${ }^{39,43,44}$ In the case of inclusion complexes with cyclodextrins, the application of ${ }^{1} \mathrm{H}$ nonselective, selective, and bi-selective spin-lattice relaxation rates can be used to address intermolecular interactions and motional dynamics of drugs encapsulated within the $\beta \mathrm{CD}$ cavity. ${ }^{45} \mathrm{~A}$ theoretical description is provided for the interested reader in the SI. Basically, measuring $\mathrm{R}_{1}^{\mathrm{NS}}$ and $\mathrm{R}_{1}^{\mathrm{SE}}$ within the initial rate approximation it is possible to infer the molecular rotational correlation time $\tau_{C}$ of the encapsulated drug, which may be thought of as the average time required for the molecule to rotate by approximately 1 radian. ${ }^{36,38,46}$ Both the $\mathrm{R}_{1}^{\mathrm{NS}} / \mathrm{R}_{1}^{\mathrm{SE}}$ ratio and $\tau_{C}$ are related to the motional regime of the guest, which in turns reflects its equilibrium between the free and bound states. $^{28,35,45}$

Here we applied this method to get information about the dynamics of the selected VOCs in reline and on how it changes in the presence and absence of $\beta$-cyclodextrin. As overlapping peaks are not suitable for selective inversion, after investigation of ${ }^{1} \mathrm{H}$ NMR spectrum, the most isolated peaks were chosen for observation, namely protons $\mathrm{H}_{3}, \mathrm{H}_{5}$ for aniline and methyl protons for toluene (see Figs. 2 and S1-S2). Figure 3 shows as an example the stack plots obtained with conventional nonselective pulses in the $180^{\circ}-t-90^{\circ}$ IR sequence (a) and with a selective IR experiment with the selective $180^{\circ}$ centered on protons $\mathrm{H}_{3}, \mathrm{H}_{5}$ of aniline (b). In Fig. 3(b), the signals of unselected protons remain essentially unperturbed, but the resonance of the selected protons relaxes faster. The values of the $R_{1}^{N S} / R_{1}^{S E}$ ratio obtained for samples 1 to 4 are summarized in Table 2. 

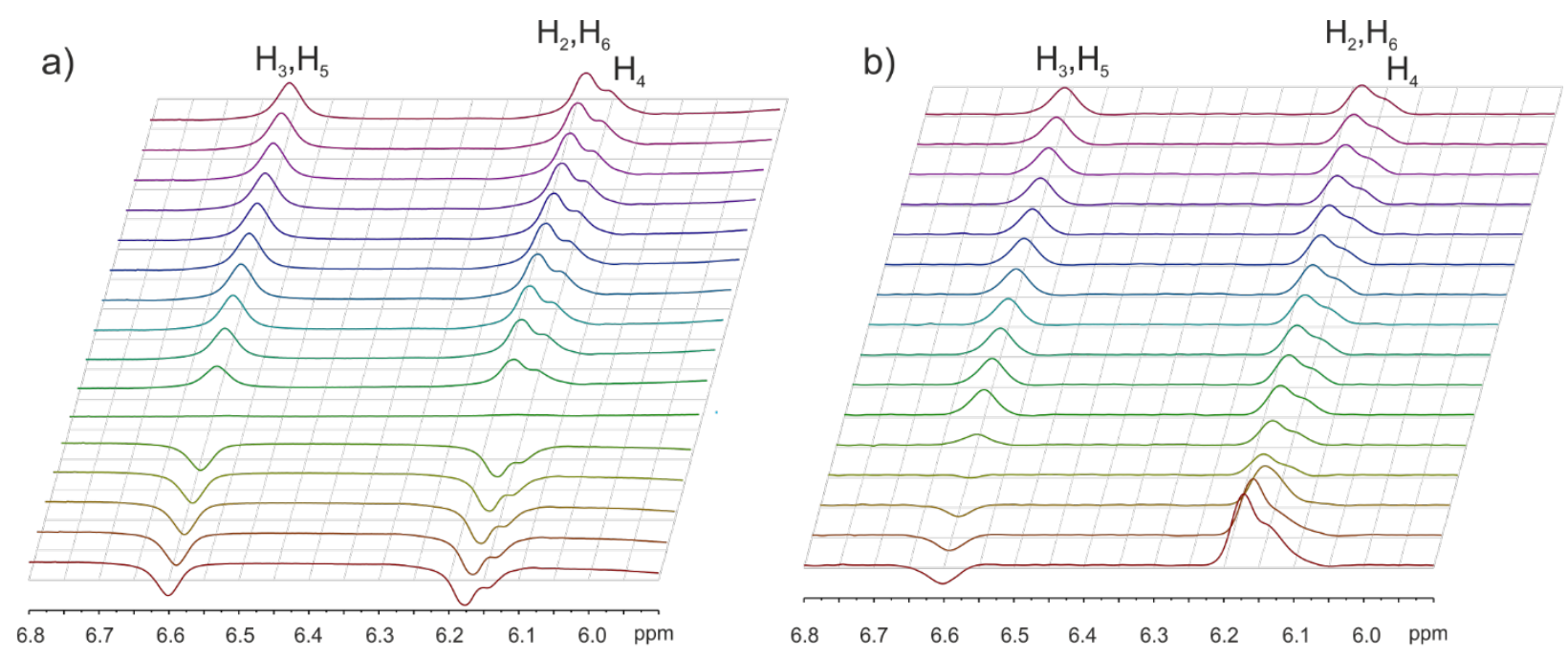

c)

d)
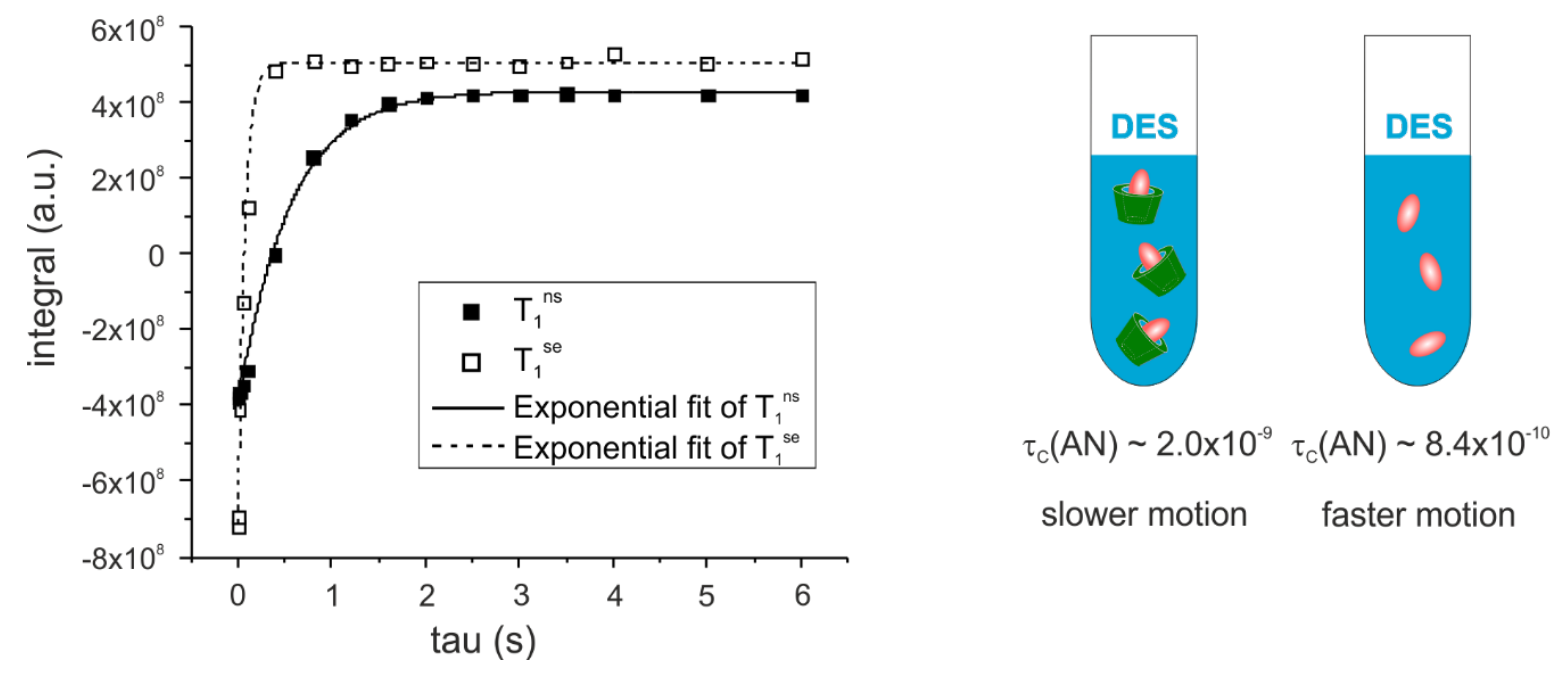

Figure 3. Stack plots of (a) nonselective and (b) selective for $\mathrm{H}_{3}, \mathrm{H}_{5}$ protons of $\mathrm{AN}$ inversion recovery experiments of sample $\mathrm{ChU} / \beta \mathrm{CD} / \mathrm{AN}$. (c) $\mathrm{T}_{1}$ relaxation decays of $\mathrm{H}_{3}, \mathrm{H}_{5}$ protons of $\mathrm{AN}$ measured with nonselective and selective inversion recovery experiments and corresponding mono-exponential fits. (d) Comparison of correlation times estimated for AN in the samples $\mathrm{ChU} / \beta \mathrm{CD} / \mathrm{AN}$ and ChU/AN. Maximum errors are estimated to be about $20 \%$. 
Table 2. $\mathrm{R}_{1}^{\mathrm{NS}} / \mathrm{R}_{1}^{\mathrm{SE}}$ ratio and $\tau_{C}$ values obtained for aniline (AN) and toluene (Tol) dissolved in reline mixtures. Maximum errors are estimated to be $10 \%$ and $20 \%$ for the hydrated and nonhydrated samples, respectively.

\begin{tabular}{|l|l|l|l|l|l|}
\hline Sample & Short name & Guest & Selected proton(s) & $\mathbf{R}_{\mathbf{1}}^{\mathbf{N S}} / \mathbf{R}_{\mathbf{1}}^{\mathbf{S E}}$ & $\boldsymbol{\tau}_{\boldsymbol{C}}(\mathbf{s})$ \\
\hline $\mathbf{1}$ & $\mathrm{ChU} / \mathrm{\beta CD} / \mathrm{AN}$ & $\mathrm{AN}$ & $\mathrm{H}_{3}, \mathrm{H}_{5}$ & 0.13 & $2.0 \times 10^{-9}$ \\
\hline $\mathbf{2}$ & $\mathrm{ChU} / \mathrm{AN}$ & $\mathrm{AN}$ & $\mathrm{H}_{3}, \mathrm{H}_{5}$ & 0.50 & $8.4 \times 10^{-10}$ \\
\hline $\mathbf{3}$ & $\mathrm{ChU} / \mathrm{\beta CD} / \mathrm{Tol}$ & $\mathrm{Tol}$ & $\mathrm{CH}_{3}$ & 0.04 & $3.9 \times 10^{-9}$ \\
\hline $\mathbf{4}$ & $\mathrm{ChU} / \mathrm{Tol}$ & $\mathrm{Tol}$ & $\mathrm{CH}_{3}$ & 0.39 & $1.0 \times 10^{-9}$ \\
\hline $\mathbf{5}$ & $\mathrm{ChU} / \beta \mathrm{CD} / \mathrm{H}_{2} \mathrm{O} / \mathrm{AN}$ & $\mathrm{AN}$ & $\mathrm{H}_{3}, \mathrm{H}_{5}$ & 0.83 & $4.8 \times 10^{-10}$ \\
\hline $\mathbf{6}$ & $\mathrm{ChU} / \mathrm{H}_{2} \mathrm{O} / \mathrm{AN}$ & $\mathrm{AN}$ & $\mathrm{H}_{3}, \mathrm{H}_{5}$ & 1.37 & $1.2 \times 10^{-10}$ \\
\hline $\mathbf{7}$ & $\mathrm{ChU} / \mathrm{\beta CD} / \mathrm{H}_{2} \mathrm{O} / \mathrm{Tol}$ & $\mathrm{Tol}$ & $\mathrm{CH}_{3}$ & 0.74 & $5.7 \times 10^{-10}$ \\
\hline $\mathbf{8}$ & $\mathrm{ChU} / \mathrm{H}_{2} \mathrm{O} / \mathrm{Tol}$ & Tol & $\mathrm{CH}_{3}$ & 0.93 & $4.1 \times 10^{-10}$ \\
\hline
\end{tabular}

In all four samples the $\mathrm{R}_{1}^{\mathrm{NS}} / \mathrm{R}_{1}^{\mathrm{SE}}$ ratio is far smaller than 1 . This is symptomatic of slow motion regime, which was expected for such viscous systems. For both aniline and toluene the $\mathrm{R}_{1}^{\mathrm{NS}} / \mathrm{R}_{1}^{\mathrm{SE}}$ ratio decreases from the pure reline to the reline $/ \beta C D$ mixture. This indicates that in the presence of $\beta C D$ the rotational motion of the guest gets even smaller, which is compatible with the formation of an inclusion complex. Even if it is tempting to compare the two VOCs, it should be remembered that different protons were selected for the two molecules (namely aromatic protons for aniline and methyl protons for toluene) and a direct comparison might not be fair.

From the ratio of the nonselective and selective relaxation rates, it was possible to get an estimate of the correlation times of VOCs in the ChU/ $\beta \mathrm{CD}$ mixtures and to compare them with the systems without $\beta C D$. Results are reported in Table 2 and Fig 4 . For both AN and Tol, $\tau_{C}$ in the $\mathrm{ChU} / \beta \mathrm{CD}$ mixture is bigger than the corresponding value in the pure reline. Since the 
correlation time is inversely proportional to the degree of molecular mobility, that is the smaller values of $\tau_{C}$ correspond to higher molecular mobility, ${ }^{38}$ this is again compatible with a slowdown in dynamics of the guest molecule because of its encapsulation in the $\beta C D$ cavity.

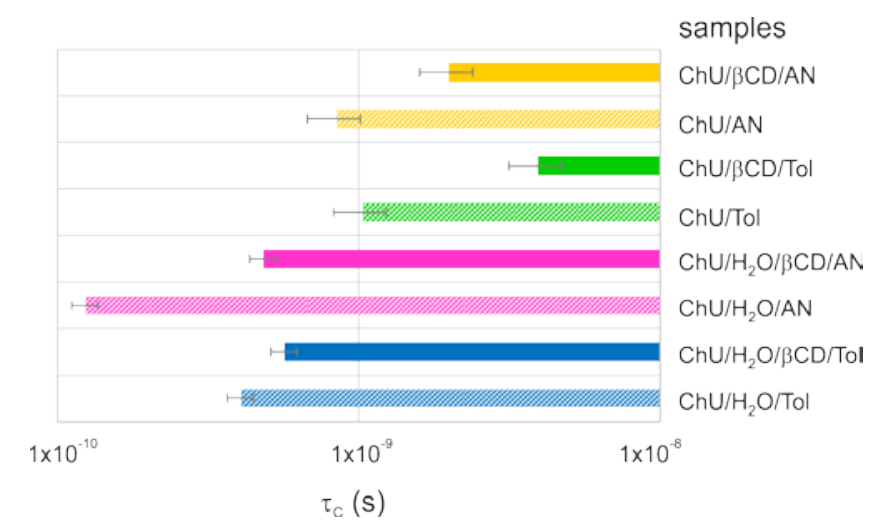

Figure 4. Summary of $\tau_{C}$ values obtained for aniline (AN) and toluene (Tol) dissolved in reline mixtures. Maximum errors are estimated to be $10 \%$ and $20 \%$ for the hydrated and non-hydrated samples, respectively.

Diffusion experiments have received attention since the mid-1990s thanks to the highly representative processing called Diffusion Ordered SpectroscopY (DOSY). ${ }^{39,47,48}$ In a DOSY map, the diffusion experiment is processed in a 2D spectrum in which one dimension is related to the chemical shift information, while the other represents the diffusion coefficient. ${ }^{49,50}$ Since the translational diffusion coefficients (D) of molecular species reflect their effective sizes and shapes, DOSY NMR allows both the identification and separation of the chemical entities in multicomponent systems, and provides information on their intermolecular interactions as well as on the dynamics of the system. ${ }^{49,51,52}$ In other words, a small molecule diffuses faster than a large one and the binding of a freely diffusing molecule to another species leads to a decrease of 
D. Indeed, in the fast exchange limit, the observed diffusion coefficient of the guest is the mole fraction weighted average of the diffusion coefficient of the free and bound states. This means that, in the presence of a complex, the diffusion of the encapsulated molecule will be slower than that measured for the free compound. DOSY maps are well suited to study aggregation and quantify molecular interactions in chemical systems, ${ }^{49,52-54}$ and many examples can be found in the literature where DOSY NMR has been used to investigate structure, stoichiometry, host bound and unbound fractions to guest, association binding constant, and host/guest relative positioning in CD complexes. ${ }^{34,49,55-58}$ DOSY maps were acquired for samples 1 to $\mathbf{4}$ (Fig. S4). Unfortunately, signals of $\beta C D$ were not detectable in any samples and VOC's signals were observed only in pure reline. This indirectly suggest that in the presence of $\beta C D$, the guest (AN or Tol) are probably encapsulated, so that their lines get broader and not visible anymore in the 2D spectra. However, no additional considerations can be drawn.

Does $\beta$-cyclodextrin form inclusion complexes with VOCs in hydrated reline mixtures?

In the previous section, practical limitations to the NMR investigation of reline/ $\beta C D$ emerged because of the inherent viscosity of the samples. Even though both the changes in ${ }^{1} \mathrm{H}$ pattern of the guest as well as the modification of its dynamic behaviour suggest that the formation of $\beta \mathrm{CD} / \mathrm{VOC}$ complexes really takes place, we do not have a direct proof of a genuine encapsulation of the VOC in the $\beta \mathrm{CD}$ cavity. To overcome this problem, we decided to add 210 equivalents of water with respect to the $\beta$-cyclodextrin in the mixture. The same NMR methodology was then applied to hydrated reline samples.

Fig. 5 shows selected regions of ${ }^{1} \mathrm{H}$ spectra of samples $\mathbf{5}$ to $\mathbf{8}$. Both VOC's and $\beta C D$ 's signals are clearly visible. In the presence of $\beta C D$, a modification of the aromatic spectral pattern of the 
guest molecule is observed, more relevant for toluene than for aniline. As for $\beta \mathrm{CD}$, if a guest molecule is incorporated into the CD cavity, one should observe modification of the chemical shift of protons $\mathrm{H}_{3}$, and $\mathrm{H}_{5}$, which are located in the hydrophobic cavity of the host molecule. Here slight changes are visible, more prominent on $\mathrm{H}_{3}$, than on $\mathrm{H}_{5}$.

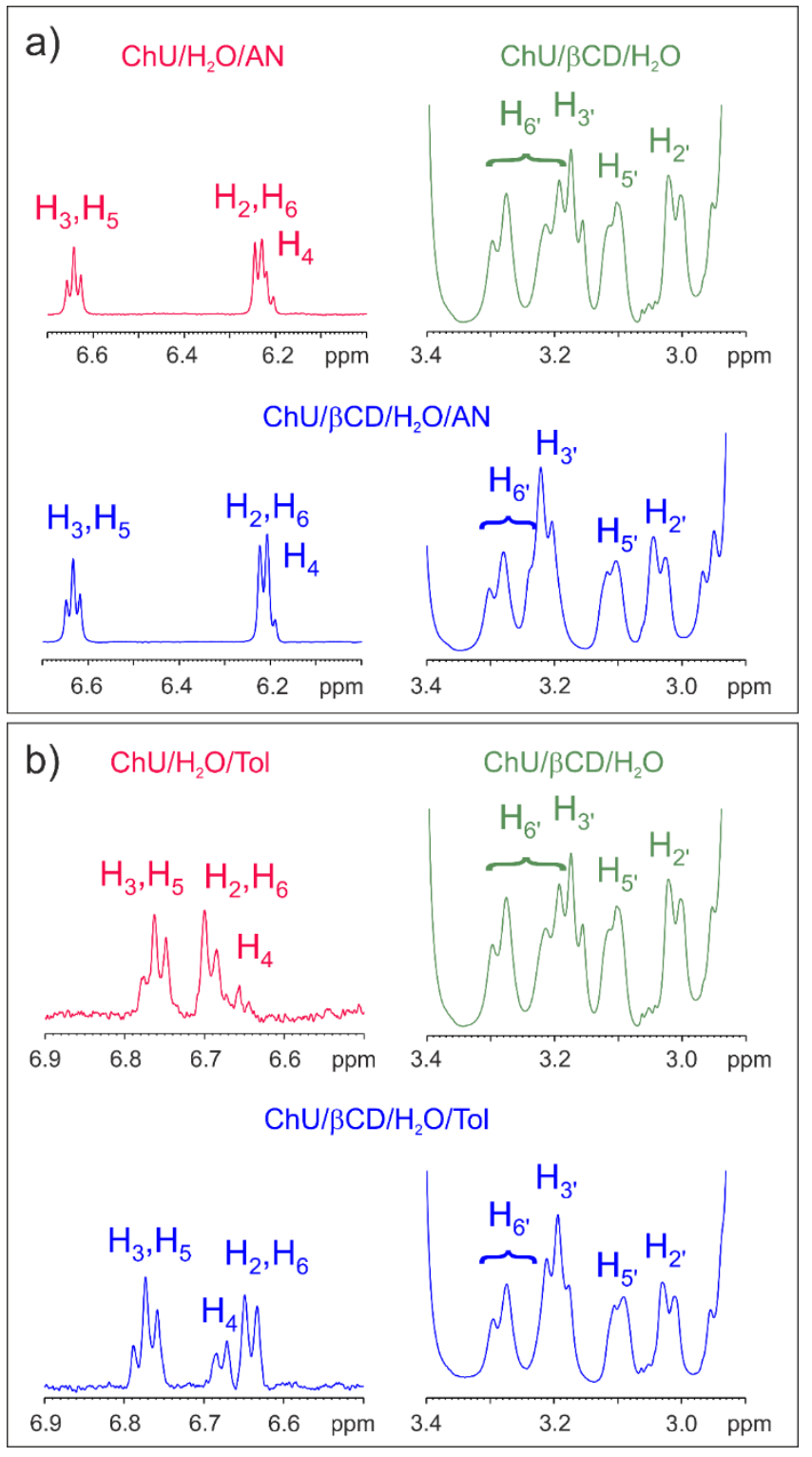

Figure 5. Comparison of ${ }^{1} \mathrm{H}$ NMR signals of the guests aniline (AN) and toluene (Tol) and the host macromolecule $\beta$-cyclodextrin ( $\beta \mathrm{CD}$ ) in different samples: (a) $\mathrm{ChU} / \beta \mathrm{CD} / \mathrm{H}_{2} \mathrm{O} / \mathrm{AN}$ (bottom spectrum, in blue) vs $\mathrm{ChU} / \mathrm{H}_{2} \mathrm{O} / \mathrm{AN}$ (top spectrum, left, in red) and $\mathrm{ChU} / \beta \mathrm{CD} / \mathrm{H}_{2} \mathrm{O}$ (top 
spectrum, right, in green); (b) $\mathrm{ChU} / \beta \mathrm{CD} / \mathrm{H}_{2} \mathrm{O} / \mathrm{Tol}$ (bottom spectrum, in blue) vs $\mathrm{ChU} / \mathrm{H}_{2} \mathrm{O} / \mathrm{Tol}$ (top spectrum, left, in red) and $\mathrm{ChU} / \beta \mathrm{CD} / \mathrm{H}_{2} \mathrm{O}$ (top spectrum, right in green).

To unambiguously confirm the encapsulation, rotating-frame Overhauser spectroscopy (ROESY) is the preferred NMR tool. ROESY studies have been extensively used to get information on inclusion complexes with $\beta \mathrm{CD}$ through analysis of intermolecular peaks between cavity protons and part of the guest involved in complexation., ${ }^{9,27,53-55,59,60}$ Fig. 6 shows representative ROESY spectra obtained for the sample $\mathrm{ChU} / \beta \mathrm{CD} / \mathrm{H}_{2} \mathrm{O} / \mathrm{AN}$ and $\mathrm{ChU} / \mathrm{\beta CD} / \mathrm{H}_{2} \mathrm{O} /$ Tol. The host-guest interactions are displayed as intermolecular correlation peaks between aromatic protons of aniline and toluene and protons $\mathrm{H}_{3}$, and $\mathrm{H}_{5}$, of $\beta C D$. This unequivocally confirms the formation of the inclusion complex of the VOC in $\beta C D$. Both AN and Tol produce larger NOEs on the $\mathrm{H}_{3}$, proton, located in the larger diameter internal part of $\beta C D$, than they did on the other internal $\mathrm{H}_{5}$, proton nearer the smaller diameter rim. This would indicate they are included through the larger diameter cavity $\beta C D$. 

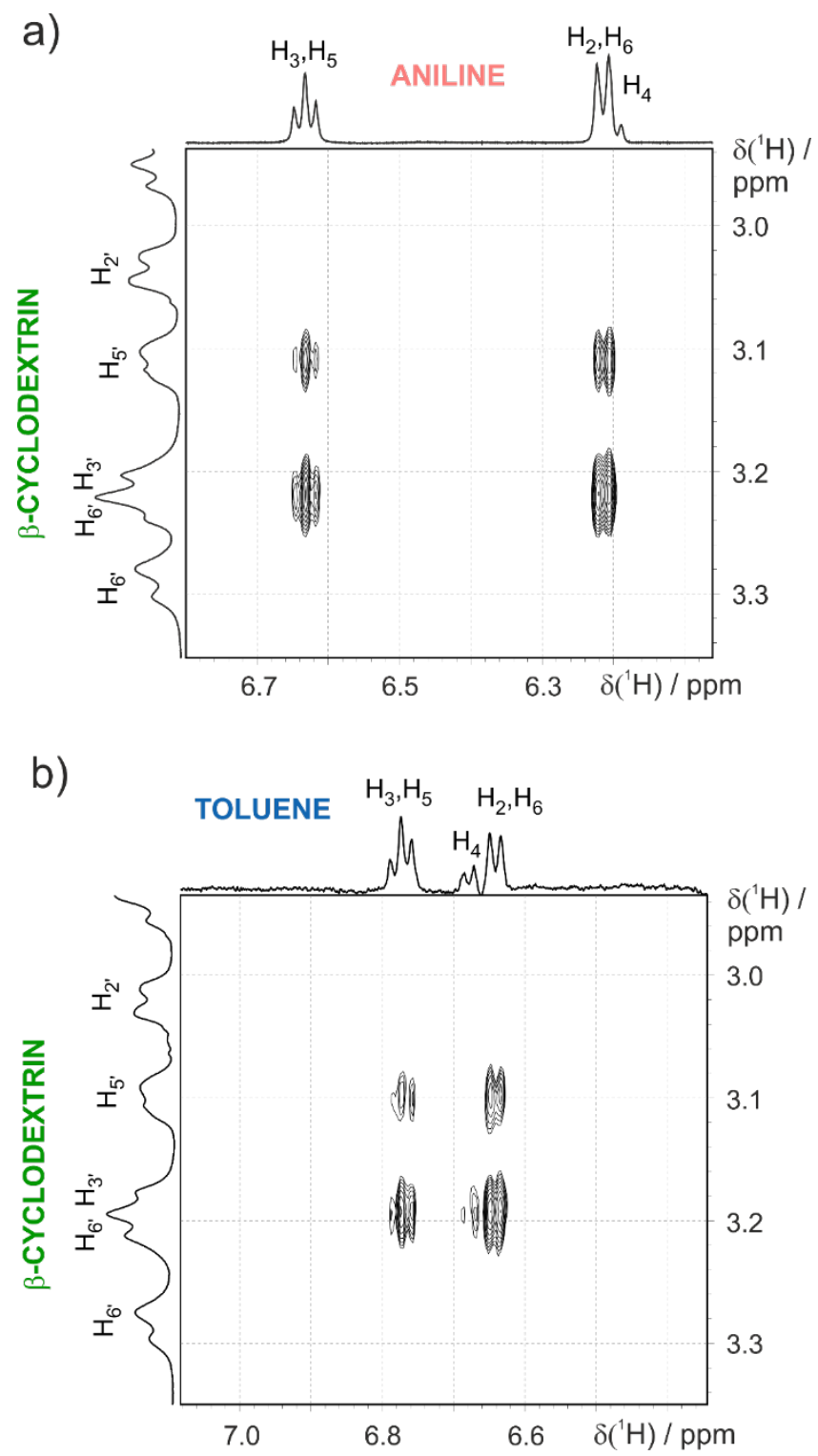

Figure 6. Selected regions of ${ }^{1} \mathrm{H}-{ }^{1} \mathrm{H}$ ROESY spectra showing intermolecular correlation peaks between signals corresponding to $\mathrm{H}_{3}$, and $\mathrm{H}_{5}$, protons of $\beta$-cyclodextrin (vertical dimension) and aromatic protons of (a) aniline and (b) toluene (horizontal dimension). 
Nonselective and selective relaxation experiments were performed on samples $\mathbf{5}$ to $\mathbf{8}$ to get dynamic information on the encapsulated VOC. Results are summarized in Table 2 and Fig. 4. Clearly, all $\mathrm{R}_{1}^{\mathrm{NS}} / \mathrm{R}_{1}^{\mathrm{SE}}$ ratios and $\tau_{C}$ values for hydrated reline mixtures are bigger than the corresponding values in non-hydrated samples. More in detail, for aniline in $\mathrm{ChU} / \beta \mathrm{CD} / \mathrm{H}_{2} \mathrm{O}$, the $\mathrm{R}_{1}^{\mathrm{NS}} / \mathrm{R}_{1}^{\mathrm{SE}}$ ratio is around 1.4. This value is expected when the molecule is in the extreme narrowing region $\left(\omega_{0} \tau_{C} \ll 1\right){ }^{38,45}$ For toluene in $\mathrm{ChU} / \beta C D / \mathrm{H}_{2} \mathrm{O}$, the value of the $\mathrm{R}_{1}^{\mathrm{NS}} / \mathrm{R}_{1}^{\mathrm{SE}}$ ratio is just close to 1 , meaning that it is in the intermediate motion limit. This would indicate that in the mixture composed of reline and water, aniline rotates more freely than toluene. Nevertheless, as different protons were selected for the two VOCs (aromatic protons for AN vs methyl protons for toluene) any further comparison would sound forced. When $\beta$-cyclodextrin is added to the mixture, the $\mathrm{R}_{1}^{\mathrm{NS}} / \mathrm{R}_{1}^{\mathrm{SE}}$ ratio and the $\tau_{C}$ values for both $\mathrm{AN}$ and Tol get smaller. Since the correlation time is inversely proportional to the degree of molecular mobility (the smaller values of $\tau_{C}$ correspond to higher molecular mobility), this is compatible with a slowdown in dynamics of the guest molecule (Tol or AN) because of its encapsulation in the $\beta C D$ cavity.

Finally, diffusion experiments were performed on samples $\mathbf{5}$ to $\mathbf{8}$. DOSY maps obtained for $\mathrm{AN}$ and Tol in reline/water mixtures, with or without $\beta \mathrm{CD}$, are reported in Figure 7. It can be seen that the diffusion of the VOC in the samples with $\beta C D$ (left column) is in both cases slower that in the corresponding samples without $\beta C D$ (right column). This is a consequence of formation of inclusion complexes with the $\beta C D$. A graphical summary of diffusion coefficients for the different species is reported in Fig. S5.

To confirm that the reduced diffusion of the guest in the presence of $\beta C D$ is not due to viscosity changes caused by the addition of the macrocyclic oligosaccharide, the self-diffusion coefficient of $\mathrm{H}_{2} \mathrm{O}$ was used as an internal reference. ${ }^{61}$ A look at Fig. S5 and Table S2 reveals 
that the diffusion coefficient of water remains constant upon addition of $\beta C D$ in the reline system. This means that the variations in solution viscosity are minimal and do not account for the change in diffusion of the guest molecules, toluene or aniline.

a)
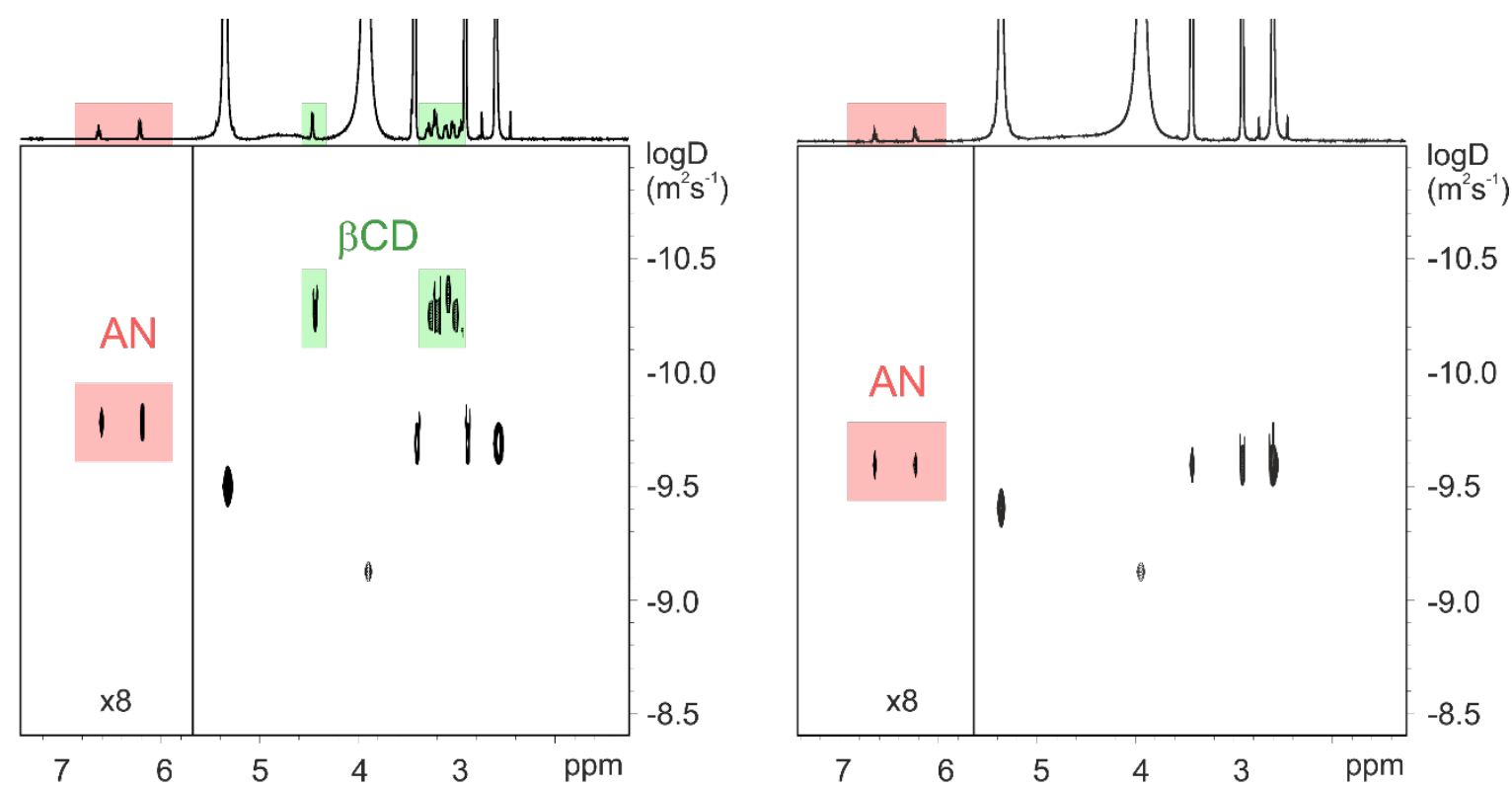

b)
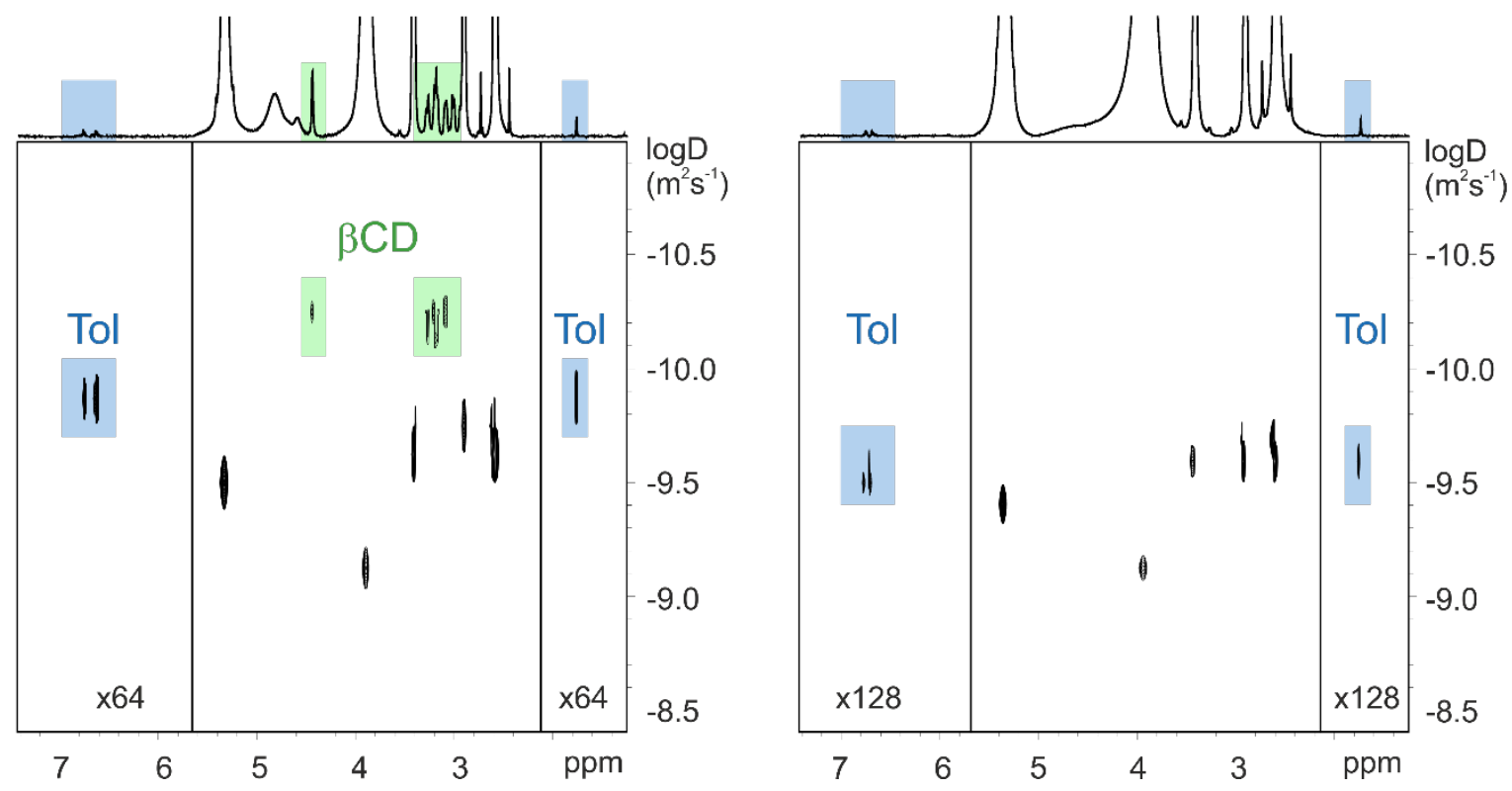
Figure 7. DOSY maps acquired for hydrated reline mixtures with (left column) and without (right column) $\beta C D$ for (a) aniline and (b) toluene.

Assuming a rapidly equilibrating system, the diffusion coefficients are weight-averaged NMR values between free and bound species. In this condition diffusion coefficients measured using DOSY experiments for the guest molecule, $\mathrm{D}_{\mathrm{G}}^{o b s}$, can be used to calculate the molar fraction of the bound guest $\mathrm{x}_{\mathrm{G}}^{\text {bound }}$ and apparent association constants $K_{a}$ of host-guest complexes (see SI for a theoretical treatment). ${ }^{50,53,55-57}$ Briefly, the observed diffusion coefficients $\left(\mathrm{D}_{\mathrm{G}}^{\text {obs }}\right.$ ) of $\mathrm{AN}$ and Tol measured in the equimolar host-guest mixtures (samples 5 and 7) are the averaged values weighted by mole fractions of their bound and free molecules. The diffusion coefficients of free guests, $\mathrm{D}_{\mathrm{G}}^{\text {free }}$, can be measured directly in the absence of the host (samples $\mathbf{6}$ and $\mathbf{8}$ ). As for the diffusion coefficients of bound guests, $\mathrm{D}_{\mathrm{G}}^{\text {bound }}$, it is typically assumed that when a small guest molecule binds to a large host molecule, the diffusion coefficient of the host is only insignificantly affected by the complexation. Therefore, the diffusion coefficient of the complex and the observed diffusion coefficient of the CD host, $\mathrm{D}_{\mathrm{H}}$, are assumed to be equal. This approximation allows to determine $K_{a}$ from a single DOSY experiment. Diffusion coefficients for $\mathrm{AN}$ and Tol are reported together with the calculated $\mathrm{x}_{\mathrm{G}}^{\text {bound }}$ and $K_{a}$ in Table 3. Taking into account the inaccuracy in the calculations coming from the different approximations and the experimental errors both in sample preparation and in the acquisition and treatment of the experimental data, the $K_{a}$ values are given with an error equal to $20 \%$ of the value. Reported values of association constant in water are in the range $140-287 \mathrm{M}^{-1}$ for $\beta C D /$ toluene and about $50 \mathrm{M}^{-1} \beta \mathrm{CD}$ /aniline, ${ }^{7}$ which are higher than the $K_{a}$ values measured here. It has been recently observed using static headspace gas chromatography (SH-GC), that association constant for the 
$\mathrm{VOC} / \beta \mathrm{CD}$ of in reline are lower than the corresponding values in water. ${ }^{26}$ However, it should be noted that also in reline $/ \mathrm{H}_{2} \mathrm{O}$ mixtures studied here, toluene binds more strongly to $\beta C D$ than aniline, which is in agreement with data from the literature. Moreover, the $K_{a}$ value found here for $\beta C D /$ toluene complex is higher than the one calculated by SH-GC $\left(79 \mathrm{M}^{-1}\right.$ vs $\left.11 \mathrm{M}^{-1}\right)$. This could be ascribed to the presence of water in the systems used in this work.

Table 3. Diffusion coefficients measured in hydrated reline mixtures and corresponding molar fraction of the bound guest $\mathrm{x}_{\mathrm{G}}^{\text {bound }}$ and apparent association constant $K_{a}$ estimated for AN and Tol

\begin{tabular}{|c|c|c|c|c|c|}
\hline Guest & $\mathrm{D}_{\mathrm{G}}^{o b s}\left(\mathrm{~m}^{2} \mathrm{~s}^{-1}\right)$ & $\mathrm{D}_{\mathrm{G}}^{\text {free }}\left(\mathrm{m}^{2} \mathrm{~s}^{-1}\right)$ & $D_{H}\left(m^{2} s^{-1}\right)$ & $\mathrm{x}_{\mathrm{G}}^{\text {bound }}$ & $K_{a}\left(\mathrm{M}^{-1}\right)$ \\
\hline $\mathrm{AN}$ & $\begin{array}{l}1.7 \times 10^{-10} \\
\pm 0.1 \times 10^{-10}\end{array}$ & $\begin{array}{l}2.6 \times 10^{-10} \\
\pm 0.1 \times 10^{-10}\end{array}$ & $\begin{array}{l}5.6 \times 10^{-11} \\
\pm 0.6 \times 10^{-11}\end{array}$ & $0.46 \pm 0.05$ & $19 \pm 4$ \\
\hline Tol & $\begin{array}{l}1.4 \times 10^{-10} \\
\pm 0.1 \times 10^{-10}\end{array}$ & $\begin{array}{l}3.2 \times 10^{-10} \\
\pm 0.2 \times 10^{-10}\end{array}$ & $\begin{array}{l}5.6 \times 10^{-11} \\
\pm 0.6 \times 10^{-11}\end{array}$ & $0.70 \pm 0.07$ & $79 \pm 16$ \\
\hline
\end{tabular}

\section{Conclusions}

$\mathrm{DES} / \beta \mathrm{CD}$ mixtures are interesting as new hybrid materials for VOC removal. To design the most performant DES-based absorbents, it is imperative to probe the formation of inclusion complexes and to have access to the dynamics of the system at the molecular level. Here we have illustrated the complementarity of the structural and dynamic information obtained from the 1D ${ }^{1} \mathrm{H}$ and ROESY spectra with diffusion and relaxation NMR experiments, and shown that their combination provides unique information to understand the formation of inclusion complexes with $\beta$-cyclodextrin in complex media such as deep eutectic systems. 
Interestingly, we have proved that a certain amount of water is beneficial in reline systems, since the viscosity of the medium is reduced, while preserving both the DES network and the complexing ability of $\beta$-cyclodextrin. In non-hydrated systems, NMR results suggest the formation of inclusion complexes but given the impossibility to obtain correlation peaks in the ROESY spectra, a direct evidence is not available. When water is added to the mixture, intermolecular peaks are clearly visible in the ROESY spectra, confirming unequivocally the inclusion of the VOC.

In both hydrated and non-hydrated samples, selective $T_{1}$ measurements turned out to be very sensitive and convenient for the investigation of the complexation of VOCs into the $\beta$ cyclodextrin, allowing the calculation of the correlation times. The $\mathrm{R}_{1}^{\mathrm{NS}} / \mathrm{R}_{1}^{\mathrm{SE}}$ ratio is a marker for the transition between dynamic states of solutes in DES systems: the border value 1.5 for molecules in the extreme narrowing limit can be exploited to monitor the transition between fast and slow tumbling solutes. The data of Table 2 related to samples $\mathbf{5}$ and $\mathbf{6}$ clearly point out that the formation of an inclusion complex between $\beta C D$ and $\mathrm{AN}$ causes the transition between fast and slow regime, not observed in the other examples of Table 2. Additionally, DOSY experiments allowed a rough but simple estimate of the molar fraction of the bound guest and the association constant of the complex in reline/water mixtures.

\section{ASSOCIATED CONTENT}

\section{Supporting Information.}

The following files are available free of charge.

Experimental details, additional NMR spectra, graphical summary of diffusion coefficients and 
theoretical background for the treatment of relaxation and diffusion data (PDF)

\section{AUTHOR INFORMATION}

\section{Corresponding Author}

* Dr. Maria Enrica Di Pietro. Phone +39 022399 3045. Email mariaenrica.dipietro@polimi.it

* Prof. Andrea Mele. Phone +39 022399 3006. Email andrea.mele@polimi.it

\section{Author Contributions}

The manuscript was written through contributions of all authors. All authors have given approval to the final version of the manuscript.

\section{ACKNOWLEDGMENT}

The work has been carried out within the frame of the bilateral France-Italy Galileo Programme (Grant G18-392 and 39467XJ). G.C.D. thanks Politecnico di Milano for her Inter-Departments PhD scholarship. The authors thank Tarek Moufawad for helpful discussion.

\section{REFERENCES}

1. Faisal I. Khan, Ghoshal AK. Removal of volatile organic compounds from polluted air. $J$ Loss Prev Process Ind. 2000;13(13):527-545.

2. Alzate-Sánchez DM, Smith BJ, Alsbaiee A, Hinestroza JP, Dichtel WR. Cotton fabric functionalized with a $\beta$-cyclodextrin polymer captures organic pollutants from contaminated air and water. Chem Mater. 2016;28(22):8340-8346. doi:10.1021/acs.chemmater.6b03624 
3. Celebioglu A, Sen HS, Durgun E, Uyar T. Molecular entrapment of volatile organic compounds (VOCs) by electrospun cyclodextrin nanofibers. Chemosphere. 2016;144:736744. doi:10.1016/j.chemosphere.2015.09.029

4. Finlayson-Pitts BJ. Tropospheric Air Pollution: Ozone, Airborne Toxics, Polycyclic Aromatic Hydrocarbons, and Particles. Science (80- ). 1997;276(5315):1045-1051. doi:10.1126/science.276.5315.1045

5. Celebioglu A, Ipek S, Durgun E, Uyar T. Selective and Efficient Removal of Volatile Organic Compounds by Channel-type Gamma-Cyclodextrin Assembly through Inclusion Complexation. Ind Eng Chem Res. 2017;56(25):7345-7354. doi:10.1021/acs.iecr.7b01084

6. Landy D, Mallard I, Ponchel A, Monflier E, Fourmentin S. Remediation technologies using cyclodextrins: An overview. Environ Chem Lett. 2012;10(3):225-237. doi:10.1007/s10311-011-0351-1

7. Kfoury M, Landy D, Fourmentin S. Characterization of cyclodextrin/volatile inclusion complexes: A review. Molecules. 2018;23(5):1-23. doi:10.3390/molecules23051204

8. Blach P, Fourmentin S, Landy D, Cazier F, Surpateanu G. Cyclodextrins: A new efficient absorbent to treat waste gas streams. Chemosphere. 2008;70(3):374-380. doi:10.1016/j.chemosphere.2007.07.018

9. Srinivasan K, Stalin T. Study of inclusion complex between 2,6-dinitrobenzoic acid and $\beta$ cyclodextrin by 1H NMR, 2D 1H NMR (ROESY), FT-IR, XRD, SEM and photophysical methods. Spectrochim Acta - Part A Mol Biomol Spectrosc. 2014;130:105-115. doi:10.1016/j.saa.2014.03.106 
10. Alsbaiee A, Smith BJ, Xiao L, Ling Y, Helbling DE, Dichtel WR. Rapid removal of organic micropollutants from water by a porous $\beta$-cyclodextrin polymer. Nature. 2016;529(7585):190-194. doi:10.1038/nature16185

11. Wang L, Kang Y, Xing CY, et al. B-Cyclodextrin based air filter for high-efficiency filtration of pollution sources. J Hazard Mater. 2019;373(September 2018):197-203. doi:10.1016/j.jhazmat.2019.03.087

12. Szaniszló N, Fenyvesi É, Balla J. Structure-stability study of cyclodextrin complexes with selected volatile hydrocarbon contaminants of soils. J Incl Phenom Macrocycl Chem. 2005;53(3):241-248. doi:10.1007/s10847-005-0245-6

13. Morin-Crini N, Crini G. Environmental applications of water-insoluble $\beta$-cyclodextrinepichlorohydrin polymers. Prog Polym Sci. 2013;38(2):344-368. doi:10.1016/j.progpolymsci.2012.06.005

14. Mauri-Aucejo AR, Llobat-Estellés M, Egea MG, Guillem C, Amorós P. Samplers for VOCs in air based on cyclodextrin-silica hybrid microporous solid phases. Analyst. 2012;137(5):1275-1283. doi:10.1039/c2an16065j

15. Moura L, Moufawad T, Ferreira M, et al. Deep eutectic solvents as green absorbents of volatile organic pollutants. Environ Chem Lett. 2017;15(4):747-753. doi:10.1007/s10311017-0654-y

16. Sze LL, Pandey S, Ravula S, et al. Ternary deep eutectic solvents tasked for carbon dioxide capture. ACS Sustain Chem Eng. 2014;2(9):2117-2123. doi:10.1021/sc5001594

17. Li Z, Wang L, Li C, et al. Absorption of Carbon Dioxide Using Ethanolamine-Based Deep 
Eutectic Solvents. ACS Sustain Chem Eng. 2019;7(12):10403-10414. doi:10.1021/acssuschemeng.9b00555

18. Zhong F-Y, Peng H-L, Tao D-J, Wu P-K, Fan J-P, Huang K. Phenol-Based Ternary Deep Eutectic Solvents for Highly Efficient and Reversible Absorption of NH3. ACS Sustain Chem Eng. 2019;7(3):3258-3266. doi:10.1021/acssuschemeng.8b05221

19. Francisco M, Van Den Bruinhorst A, Kroon MC. Low-transition-temperature mixtures (LTTMs): A new generation of designer solvents. Angew Chemie - Int Ed. 2013;52(11):3074-3085. doi:10.1002/anie.201207548

20. Abbott AP, Capper G, Davies DL, Rasheed RK, Tambyrajah V. Novel solvent properties of choline chloride / urea mixtures. Chem Commun. 2003:70-71. doi:10.1039/B210714G

21. Ruß C, König B. Low melting mixtures in organic synthesis - An alternative to ionic liquids? Green Chem. 2012;14(11):2969-2982. doi:10.1039/c2gc36005e

22. Zhang Q, De Oliveira Vigier K, Royer S, Jérôme F. Deep eutectic solvents: syntheses, properties and applications. Chem Soc Rev. 2012;41(21):7108-7146. doi:10.1039/c2cs35178a

23. Liu Y, Friesen JB, McAlpine JB, Lankin DC, Chen SN, Pauli GF. Natural Deep Eutectic Solvents: Properties, Applications, and Perspectives. J Nat Prod. 2018;81(3):679-690. doi:10.1021/acs.jnatprod.7b00945

24. Pena-Pereira F, Namieśnik J. Ionic liquids and deep eutectic mixtures: Sustainable solvents for extraction processes. ChemSusChem. 2014;7(7):1784-1800. doi:10.1002/cssc.201301192 
25. Cruz H, Jordão N, Branco LC. Deep eutectic solvents (DESs) as low-cost and green electrolytes for electrochromic devices. Green Chem. 2017;19(7):1653-1658. doi:10.1039/c7gc00347a

26. Moufawad T, Moura L, Ferreira M, et al. First Evidence of Cyclodextrin Inclusion Complexes in a Deep Eutectic Solvent. ACS Sustain Chem Eng. 2019;7(6):6345-6351. doi:10.1021/acssuschemeng.9b00044

27. Schneider H-J, Hacket F, Rüdiger V, Ikeda H. NMR Studies of Cyclodextrins and Cyclodextrin Complexes. Chem Rev. 1998;98(5):1755-1786. doi:10.1021/cr970019t

28. Li Y, Yin G, Wei W, et al. Interactions of Lycopodium alkaloids with acetylcholinesterase investigated by 1H NMR relaxation rate. Biophys Chem. 2007;129(2-3):212-217. doi:10.1016/j.bpc.2007.05.020

29. Reddy RR, Phani Kumar BVN, Shanmugam G, Madhan B, Mandal AB. Molecular Level Insights on Collagen-Polyphenols Interaction Using Spin-Relaxation and Saturation Transfer Difference NMR. J Phys Chem B. 2015;119(44):14076-14085. doi:10.1021/acs.jpcb.5b07911

30. Marques HMC. A review on cyclodextrin encapsulation of essential oils and volatiles. Flavour Fragr J. 2010;25(5):313-326. doi:10.1002/ffj.2019

31. Posada E, López-Salas N, Jiménez Riobóo RJ, Ferrer ML, Gutiérrez MC, Del Monte F. Reline aqueous solutions behaving as liquid mixtures of H-bonded co-solvents: Microphase segregation and formation of co-continuous structures as indicated by Brillouin and1H NMR spectroscopies. Phys Chem Chem Phys. 2017;19(26):17103-17110. 
doi:10.1039/с7cp02180a

32. Hammond OS, Bowron DT, Edler KJ. The Effect of Water upon Deep Eutectic Solvent Nanostructure: An Unusual Transition from Ionic Mixture to Aqueous Solution. Angew Chemie - Int Ed. 2017;56(33):9782-9785. doi:10.1002/anie.201702486

33. Colombo Dugoni G, Di Pietro ME, Ferro M, et al. Effect of Water on Deep Eutectic Solvent/B-Cyclodextrin Systems. ACS Sustain Chem Eng. 2019;7:7277-7285. doi:10.1021/acssuschemeng.9b00315

34. Tošner Z, Aski SN, Kowalewski J. Rotational dynamics of adamantanecarboxylic acid in complex with $\beta$-cyclodextrin. J Incl Phenom Macrocycl Chem. 2006;55(1-2):59-70. doi:10.1007/s10847-005-9019-4

35. Freeman R, Hill HDW, Tomlinson BL, Hall LD. Dipolar contribution to NMR spin lattice relaxation of protons. $J$ Chem Phys. 1974;61(11):4466-4473. doi:10.1063/1.1681764

36. Hall LD, Hill HDW. Spin-Lattice Relaxation of Protons. A General, Quantitative Evaluation of Contributions from the Intramolecular Dipole-Dipole Mechanism. $J$ Am Chem Soc. 1976;98(5):1269-1270. doi:10.1016/b978-0-408-01434-2.50020-6

37. Gaggelli E, Gaggelli N, Maccotta A, Valensin G. 1H Relaxation Investigation of the Interaction of Vinblastine with Tubulin. J Magn Reson. 1994;104:89-94.

38. Tinoco LW, Figueroa-Villar JD. Determination of Correlation Times from Selective and Non-Selective Spin-Lattice Relaxation Rates and their Use in Drug-Drug and DrugAlbumin Interaction Studies. J Braz Chem Soc. 1999;10(4):281-286. doi:10.1590/S0103- 
50531999000400005

39. Fielding L. NMR methods for the determination of protein-ligand dissociation constants. Prog Nucl Magn Reson Spectrosc. 2007;51(4):219-242. doi:10.1016/j.pnmrs.2007.04.001

40. Bain AD. Chemical exchange in NMR. Prog Nucl Magn Reson Spectrosc. 2003;43(34):63-103. doi:10.1016/j.pnmrs.2003.08.001

41. Rossi C, Pogliani L, Laschi F, Niccolai N. Proton magnetic relaxation mechanisms and solution dynamics of L-histidine. J Chem Soc Faraday Trans 1 Phys Chem Condens Phases. 1983;79(12):2955-2959. doi:10.1039/F19837902955

42. Sai T, Takao N, Sugiurat M. Application of 'H NMR Selective and Biselective Relaxation Times. Magn Reson Chem. 1992;30(June):1041-1046.

43. Rossi C, Bonechi C, Martini S, et al. Ligand-macromolecule complexes: Affinity index determination by selective nuclear relaxation analysis. Magn Reson Chem. 2001;39(8):457-462. doi:10.1002/mrc.876

44. Bonechi C, Martini S, Brizzi V, et al. Nuclear magnetic resonance for studying recognition processes between anandamide and cannabinoid receptors. Eur J Med Chem. 2006;41(10):1117-1123. doi:10.1016/j.ejmech.2006.05.017

45. Kumar D, Krishnan Y, Paranjothy M, Pal S. Analysis of Molecular Interaction of Drugs within $\beta$-Cyclodextrin Cavity by Solution-State NMR Relaxation. $J$ Phys Chem B. 2017;121(13):2864-2872. doi:10.1021/acs.jpcb.6b11704

46. Campbell ID, Freeman R. Influence of Cross-Relaxation on NMR Spin-Lattice Relaxation Times. J Magn Reson. 1973;11:143-162. 
47. Morris KF, Johnson CSJ. Diffusion-Ordered Two-Dimensional Nuclear Magnetic Resonance Spectroscopy. J Am Chem Soc. 1992;114(8):3139-3141.

48. Stilbs P. Fourier transform pulsed-gradient spin-echo studies of molecular diffusion. Prog Nucl Magn Reson Spectrosc. 1987;19(1):1-45. doi:10.1016/0079-6565(87)80007-9

49. Pagès G, Gilard V, Martino R, Malet-Martino M. Pulsed-field gradient nuclear magnetic resonance measurements (PFG NMR) for diffusion ordered spectroscopy (DOSY) mapping. Analyst. 2017;142(20):3771-3796. doi:10.1039/c7an01031a

50. Brand T, Cabrita EJ, Berger S. Intermolecular interaction as investigated by NOE and diffusion studies. Prog Nucl Magn Reson Spectrosc. 2005;46(4):159-196. doi:10.1016/j.pnmrs.2005.04.003

51. Senra TDA, Khoukh A, Desbrières J. Interactions between quaternized chitosan and surfactant studied by diffusion NMR and conductivity. Carbohydr Polym. 2017;156:182192. doi:10.1016/j.carbpol.2016.09.025

52. Barhoum S, Palit S, Yethiraj A. Diffusion NMR studies of macromolecular complex formation, crowding and confinement in soft materials. Prog Nucl Magn Reson Spectrosc. 2016;94-95:1-10. doi:10.1016/j.pnmrs.2016.01.004

53. Fernandes SA, Cabeça LF, Marsaioli AJ, De Paula E. Investigation of tetracaine complexation with beta-cyclodextrins and p-sulphonic acid calix[6]arenes by nOe and PGSE NMR. J Incl Phenom Macrocycl Chem. 2007;57(1-4):395-401. doi:10.1007/s10847-006-9224-9

54. Simova S, Berger S. Diffusion measurements vs. chemical shift titration for determination 
of association constants on the example of camphor-cyclodextrin complexes. $J$ Incl Phenom Macrocycl Chem. 2005;53(3):163-170. doi:10.1007/s10847-005-2631-5

55. Lis-Cieplak A, Sitkowski J, Kolodziejski W. Comparative proton nuclear magnetic resonance studies of amantadine complexes formed in aqueous solutions with three major cyclodextrins. J Pharm Sci. 2014;103(1):274-282. doi:10.1002/jps.23802

56. Martins L, Arrais M, De Souza A, Marsaioli A. 1H NMR studies of binary and ternary dapsone supramolecular complexes with different drug carriers: EPC liposome, SBE- $\beta$ CD and $\beta$-CD. Magn Reson Chem. 2014;52(11):665-672. doi:10.1002/mrc.4087

57. Uccello-Barretta G, Balzano F, Paolino D, Ciaccio R, Guccione S. Combined NMRcrystallographic and modelling investigation of the inclusion of molsidomine into $\alpha-, \beta$ and $\quad \gamma$-cyclodextrins. Bioorganic Med Chem. 2005;13(23):6502-6512. doi:10.1016/j.bmc.2005.07.009

58. Kfoury M, Landy D, Ruellan S, Auezova L, Greige-Gerges H, Fourmentin S. Determination of formation constants and structural characterization of cyclodextrin inclusion complexes with two phenolic isomers: Carvacrol and thymol. Beilstein J Org Chem. 2016;12:29-42. doi:10.3762/bjoc.12.5

59. Ali SM, Fatma K, Dhokale S. Structure elucidation of $\beta$-cyclodextrin-xylazine complex by a combination of quantitative $1 \mathrm{H}-1 \mathrm{H}$ ROESY and molecular dynamics studies. Beilstein J Org Chem. 2013;9:1917-1924. doi:10.3762/bjoc.9.226

60. Ali SM, Shamim S. Analysis of computational models of $\beta$-cyclodextrin complexes: Structural studies of morniflumate hydrochloride and $\beta$-cyclodextrin complex in aqueous 
solution by quantitative ROESY analysis. J Incl Phenom Macrocycl Chem. 2015;83(12):19-26. doi:10.1007/s10847-015-0534-7

61. Silva M, Figueiredo AM, Cabrita EJ. Epitope mapping of imidazolium cations in ionic liquid-protein interactions unveils the balance between hydrophobicity and electrostatics towards protein destabilisation. Phys Chem Chem Phys. 2014;16(42):23394-23403. doi:10.1039/с4cp03534h

\section{SYNOPSIS}

The combination of the $1 \mathrm{D}{ }^{1} \mathrm{H}$ and ROESY spectra with diffusion and relaxation NMR experiments provides unique structural and dynamic information on inclusion complexes in $\mathrm{DES} / \beta C D$ mixtures, crucial for the design of task-specific sustainable absorbents.

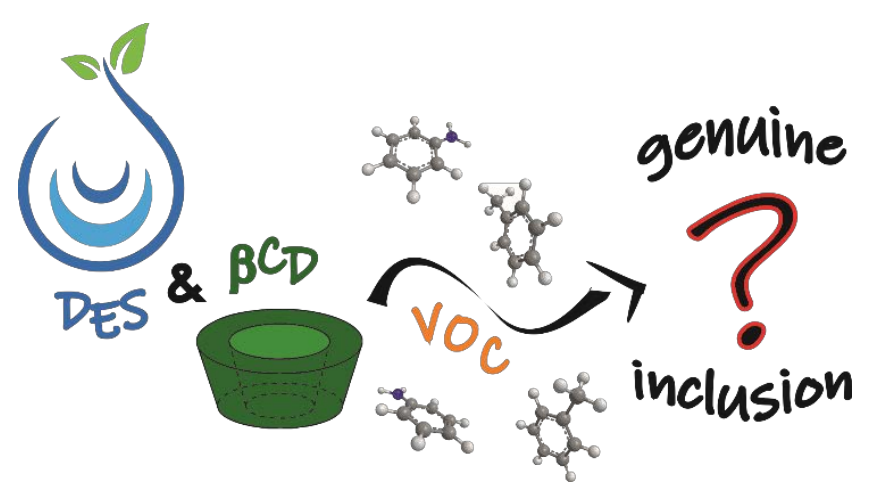

